\title{
ERRATUM
}

\section{Longitudinal association between infant disorganized attachment and childhood posttraumatic stress symptoms}

\author{
HELEN Z. MACDONALD,$^{a, b}$ MARJORIE BEEGHLY, ${ }^{c-e}$ \\ WANDA GRANT-KNIGHT, ${ }^{f}$ MARILYN AUGUSTYN,${ }^{a}$ RYAN W. WOODS,${ }^{g}$ \\ HOWARD CABRAL, ${ }^{a}$ RUTH ROSE-JACOBS,${ }^{a}$ GLENN N. SAXE,${ }^{d, e}$ AND \\ DEBORAH A. FRANK ${ }^{a}$ \\ ${ }^{a}$ Boston University; ${ }^{b}$ VA Boston Healthcare System; ${ }^{c}$ Wayne State University; ${ }^{d}$ Children's \\ Hospital Boston; ${ }^{e}$ Harvard University; ${ }^{f}$ Rehabilitation Institute of Chicago; and ${ }^{g}$ University \\ of Wisconsin
}

The corresponding author's affiliation was incorrect in the original article published in issue 2 of this year. The title page with her correct affiliation is reprinted here. We regret this error and any problems it may have caused.

\begin{abstract}
The purpose of this study was to evaluate whether children with a history of disorganized attachment in infancy were more likely than children without a history of disorganized attachment to exhibit symptoms of posttraumatic stress disorder (PTSD) at school age following trauma exposure. The sample consisted of 78 8.5-year-old children from a larger, ongoing prospective study evaluating the effects of intrauterine cocaine exposure (IUCE) on children's growth and development from birth to adolescence. At the 12-month visit, children's attachment status was scored from videotapes of infant-caregiver dyads in Ainsworth's strange situation. At the 8.5-year visit, children were administered the Violence Exposure Scale-Revised, a child-report trauma exposure inventory, and the Diagnostic Interview for Children and Adolescents by an experienced clinical psychologist masked to children's attachment status and IUCE status. Sixteen of the 78 children $(21 \%)$ were classified as insecure-disorganized/insecure-other at 12 months. Poisson regressions covarying IUCE, gender, and continuity of maternal care indicated that disorganized attachment status at 12 months, compared with nondisorganized attachment status, significantly predicted both higher avoidance cluster PTSD symptoms and higher reexperiencing cluster PTSD symptoms. These findings suggest that the quality of early dyadic relationships may be linked to differences in children's later development of posttraumatic stress symptoms following a traumatic event.
\end{abstract}

Epidemiological research indicates that approximately $60 \%$ of men and $50 \%$ of women experience at least one traumatic event over the

The research presented in this paper was supported, in part, by a grant from the National Institute of Drug Abuse (R01DA6532) to Deborah A. Frank, Principal Investigator, and a grant from NIH/NCRR (M01RR00533). The authors are grateful to the families for their participation in this study. We also acknowledge the research staff in the developmental lab at Boston Medical Center for their valuable assistance with data collection and reduction in this project and Dr. Heidi Ellis who kindly edited earlier versions of this paper. course of their lives (Kessler, Sonnega, Bromet, Hughes, \& Nelson, 1995). However, only $5 \%$ of men and $10 \%$ of women go on to develop posttraumatic stress disorder (PTSD; Kessler et al., 1995). Although there is scant epidemiological research examining these questions in children, preliminary research investigating the population prevalence of childhood exposure to trauma

Address correspondence and reprint requests to: Helen Z. MacDonald, Behavioral Sciences Division, National Center for PTSD, VA Boston Healthcare System, 150 South Huntington Avenue, 116B-4, Boston, MA 02130 